\title{
Why does epistemic must need indirect evidence, and is it logically strong or weak?
}

Introduction $^{1} \quad$ Epistemic must (1) has two interesting features.

(1) It must be raining.

First, it seems to require indirect evidence: (1) is only felicitous if we see people entering with wet umbrellas, not if we are standing in the downpour. Second, must often sounds more tentative than the bare prejacent, "it's raining" (Karttunen 1972).

Yet paradoxically, must can also be used in cases where the prejacent is necessarily true, and in such cases can even sound emphatic:

(2) The oil is floating on the water, so it must be less dense than the water.

These two observations create three questions that a semantic analysis ought to solve. First, why does must require indirect evidence? Since strong epistemic modals in many languages share this requirement (von Fintel \& Gillies 2010), it should not be stipulated as a quirk of must. Second, what is the logical relationship between $\operatorname{must}(\phi)$ and $\phi$ ? Does $\phi$ entail must $(\phi)$, as suggested by Karttunen 1972 and Kratzer 1981 - making must logically "weak"? Or does $\operatorname{must}(\phi)$ entail $\phi$, as argued by von Fintel \& Gillies 2010 - making must logically "strong"? Third, how does must's indirectness requirement relate to its entailment patterns? Should we analyze must as weak because it invokes indirect evidence (Karttunen 1972, Kratzer 1981); or should we separate indirectness from logical strength/weakness (von Fintel \& Gillies 2010)?

Overview I first review a prominent analysis from each side of the entailment debate: Kratzer's weak must and vF\&G's strong must. Finding that neither analysis is fully satisfactory, I suggest a way that Kratzer's analysis can be tweaked to be consistent with analyzing must as strong, weak, or neither. To accomplish this goal, I define epistemic must parallel to deontic must. This parallel reflects how epistemic must invokes descriptive generalizations, or rules of default reasoning (Stone 1994), in the same way that deontic must invokes normative generalizations. Next, I use this analysis to explain why must requires indirect evidence: a speaker is using one or more generalizations to map a fact to things that follow from it. Because the facts only support the conclusion when mediated by these generalizations, this inference process is inherently indirect. Next, I use the analysis to suggest that perhaps must "strong" in one sense and "weak" in another, so that the "strong vs. weak" question does not have a single answer. Finally, drawing on the insights of Stone, I explain the pragmatic properties of must that spark the entailment debate in the first place. Kratzer Observing that must claims sound less convincing than the unmodalized prejacent, and that must claims seem to require indirect evidence, Kratzer explains the first observation in terms of the second. She suggests must is logically weak because it invokes indirect, potentially unreliable evidence. To write this into must's denotation, Kratzer uses her framework for analyzing modality, in which all modals lexically supply a quantificational force $-\forall$ or $\exists-$ and are contextually associated with modal base (the set of worlds being quantified over) and an ordering source (which ranks the worlds by some contextually determined criteria). A modal statement claims that in all or some of the best-ranked worlds in the modal base, the prejacent is true.

\footnotetext{
${ }^{1}$ Thanks to Chris Potts, Anastasia Giannakidou, Peet Klecha, and audiences at California Universities Semantics and Pragmatics (CUSP) and the Stanford SemPrag Group.
} 
On Kratzer's view, epistemic must invokes universal quantification $(\forall)$ and a modal base of all worlds consistent with what is known. Next, turning to the ordering source, a statement like "It must be raining" signals that the speaker is invoking some indirect and potentially unreliable evidence for her conclusion; in the rain case, perhaps she is using what she remembers from the forecast. This unreliable evidence forms the ordering source for epistemic must, so that "it's raining" is true in all of the epistemically accessible worlds that are ranked highly by this ordering source. On this view, the ordering source of unreliable/indirect information both causes must to require indirect evidence and makes must logically weak.

vF\&G vF\&G object to weak must on two grounds. On a theoretical level, they point out that indirectness is distinct from logical strength or weakness. For example, must can be used to report mathematical statements which are necessarily true, even though such statements involve inference. Next, on an empirical level, they observe that must conversationally commits the speaker to the prejacent. For example, the speaker is incoherent if she denies the prejacent herself (3). Here, must conflicts with the prototypical weak epistemic modal, might.

It might/\#must be raining, but it might not be.

Therefore, $\mathrm{vF} \& \mathrm{G}$ conclude that must is strong. To capture this idea, they propose a denotation that makes must entail the prejacent. To express must's requirement for indirect evidence, they stipulate that must only quantifies over indirectly known information, which they calculate by subtracting a kernel of "directly known information" from the set of all known information. On this denotation, must $\phi$ is defined only if the direct evidence does not directly settle $\phi$, and true only if the indirect evidence entails the prejacent. For example, "it must be raining" is defined only if the direct evidence does not settle whether it is raining, and true only if the indirect evidence entails that it is raining.

But as the authors point out, it is hardly satisfying to stipulate that must's modal bases is restricted to indirectly known information. Therefore, they call their analysis a "placeholder... for the eventual solution to the mystery" of why this "pairing of epistemic modals with an indirect inference signal" persists throughout English and across languages. In contrast, the denotation I propose below does not need to stipulate indirectness in this way.

Proposal I propose to modify Kratzer's denotation in a way that derives the indirectness requirement independent of logical strength or weakness. This denotation will allow us to explain why the speaker is committed to the prejacent, why must requires indirectness, and why must can come across as either tentative or emphatic.

To arrive at this denotation for epistemic must, I take inspiration from the deontic flavor of must, as in "you must not litter." On most analyses, these two modal flavors are analyzed quite differently: epistemic must receives a modal base of "what is known" and an ordering source of questionable assumptions (Kratzer), stereotypicality, or no ordering source (vF\&G). In contrast, deontic must uses a modal base consisting of the circumstances and an ordering source ranking worlds by how well they conform with a body of normative rules.

But I suggest that these differences obfuscate something that both modals share. Both flavors of must invoke a body of rules of some sort: for deontic must, these are normative rules such as "do not litter," and for epistemic must, descriptive rules about how things tend to unfold, such as "wet umbrellas indicate rain." These descriptive generalizations, Stone suggests, can be considered defeasible inference rules (as studied by Reiter 1980, Pelletier \& Elio 1997 a.o.) - rules that are 
good enough to help us get around, but not airtight. To make this idea precise, I define a rule as a logical relationship between two sets of worlds, such as "wet umbrella worlds are rain worlds" or "good worlds are non-littering worlds." For both normative and descriptive rules, it's possible that these logical relationships are airtight - perhaps we think (normatively) slavery is unequivocally wrong, and (descriptively) prime numbers never have more than two factors. But it is also possible that these relationships are defeasible (littering may be okay if you are running from a bear; wet umbrellas may indicate rain that stopped).

I propose that epistemic must uses an ordering source of such descriptive rules, just as deontic must uses an ordering source of normative rules, as below:

(4) Epistemic must: Fix an epistemic ${ }^{2}$ modal base $B$ and an ordering source $g$ selecting all the worlds compatible with some descriptive rules

must $\phi^{B, f, w}=1$ iff $\forall w^{\prime} \in B \leq_{g(w)}, \phi\left(w^{\prime}\right)=1$

Using this denotation, I suggest that we can derive epistemic must's requirement for indirect evidence without classifying must as logically strong or weak.

Deriving indirectness On this analysis, epistemic must involves moving from facts about this world to a claim about all worlds consistent with those facts. To map these facts to this claim, must invokes a set of descriptive generalizations, so that the facts only support the prejacent when mediated by these generalizations: in other words, indirectly. This reasoning explains why must needs indirect evidence.

To illustrate how this proposal handles felicitous use of must, imagine that a speaker knows certain facts: she sees people entering with wet umbrellas. She also knows a rule mapping these facts to a conclusion: wet umbrellas indicate rain. She concludes that in all worlds consistent with the facts of this world, it is raining. To explain why she is committed to this prejacent even though the inference is defeasible, we might add that she does not consider it as a defeasible inference even though it is; for the purposes of this inference, she accepts it as universally valid.

This proposal also helps to rule out infelicitous uses of must. Imagine that the speaker knows certain facts: this time, she sees raindrops falling from the sky. She knows a rule mapping these facts to a conclusion: raindrops indicate rain. But this inference is so trivial that (as Stone observes) it is infelicitous to draw attention to it with must. On this view, indirectness no longer needs to be stipulated.

The entailment question This proposal is consistent with viewing must as logically strong if the descriptive generalizations invoked were known to be true, or - in a sense - logically weak if the generalizations were seen as fallible. But it would be quite difficult to decide if must is categorically strong or weak. It would be hard to determine whether must $(\phi)$-worlds were a subset of $\phi$-worlds or vice versa without defining $\operatorname{must}(\phi)$ first, which would beg the question. Either answer to the strong vs. weak question seems to encounter problems. Proponents of weak must would struggle to explain why must can sound emphatic, why it can report mathematical truisms, or why it commits the speaker to the prejacent. Proponents of strong must do not have an immediate explanation for why must often comes across as tentative or why it requires indirect evidence.

\footnotetext{
${ }^{2}$ In my LSA talk, I used a circumstantial modal base here because I did not see how it differed from an epistemic one; but I now think a circumstantial modal base can include facts one doesn't know or cannot predict, whereas an epistemic modal base can only include facts that one currently thinks one knows. Thanks to Peet Klecha for this conversation.
} 
Whereas the entailment question presupposes must must be unequivocally either strong or weak, I suggest that the answer to this question depends on the context and what one means by "strong" and "weak." The controversy arises from the apparent tension between tentative-sounding must ("but my keys must be in my purse!") and emphatic-sounding must ("the oil must be less dense than the water"). However, using the denotation I've proposed, it is possible to explain both of these pragmatic possibilities without categorizing must as unequivocally strong or weak. As Stone observes, must spotlights the inference that a speaker is using to deduce the prejacent from some facts. Highlighting the inference in this way may have two different consequences in the discourse. If a hearer determines that the speaker's ordering source uses questionable defeasible generalizations, he has multiple points to diverge from her reasoning: he could disagree with her premises or her inference process. Knowing this, the speaker could use must to hedge her utterance. Or, if the hearer thinks the speaker's ordering source uses valid reasoning, then he may be more convinced by the speaker's argument when he considers this reasoning. Knowing this, the speaker could use must to emphasize her certainty. On this view, must may be "strong" in the sense that it commits the speaker to the prejacent, but it can be either "strong" or "weak" in terms of how it frames the prejacent as conversational contribution. This nuanced view is only possible when we sidestep the question of whether must is categorically strong or weak.

Conclusion In sum, this analysis derives why must requires indirect evidence; why must can appear logically strong or weak; and why the strong vs. weak question presupposes a false dichotomy between those two options. As Stone emphasizes, "speakers express a variety of conclusions, some logical, some defeasible. Sometimes they express them using epistemic must, but the data suggests that this use does not reflect the different logical status of conclusions."

\section{References}

Bach, Kent. 1984. Default reasoning: Jumping to conclusions and knowing when to think twice. Pacific Philosophical Quarterly, 65, 37-58.

Cohen, Ariel. 1999. Generics, frequency adverbs, and probability. Linguistics and Philosophy, 22, $221-253$.

Hacquard, Valentine, \& Wellwood, Alexis. 2012. Embedding epistemic modals in English: A corpus-based-study. Semantics and Pragmatics, 5(4), 1-29.

Karttunen, Lauri. 1972. Possible and must. Pages 1-20 of: Kimball, J. (ed), Syntax and Semantics, vol. 1. New York: Academic Press.

Kratzer, Angelika. 1981. The notional category of modality. Pages 38-74 of: Eikmeyer, H.-J., \& Rieser, H. (eds), Words, Worlds, and Context. de Gruyter.

Matthewson, Lisa, Davis, Henry, \& Rullmann, Hotze. 2008. Evidentials as epistemic modals: Evidence from St'at'imcets. Linguistic Variation Yearbook, 7.

Pelletier, Francis Jeffrey, \& Elio, Renee. 1997. What should default reasoning be, by default? Computational Intelligence, 13(2), 165-187.

Portner, Paul. 2009. Modality. Studies in Semantics and Pragmatics. Oxford University Press.

Reiter, R. 1980. A logic for default reasoning. Artificial Intelligence, 13, 81-132.

Stone, Matthew. 1994. The reference argument of epistemic must. Pages 181-190 of: Proceedings of the International Workshop on Computational Semantics (IWCS) 1.

Swanson, Eric. 2008. Modality in language. Philosophy Compass, 3, 1193-1207.

von Fintel, Kai. 2012. The best we can (expect to) get? Challenges to the classic semantics for deontic modals. Manuscript, MIT.

von Fintel, Kai, \& Gillies, Anthony. 2010. 'Must' . . stay . . . strong! Natural Language Semantics, 18, $351-383$.

Westmoreland, Robert. 1995. Epistemic must as evidential. Pages 683-702 of: Proceedings of the Amsterdam Colloquium, vol. 10.

Willer, Malte. To appear. An update on epistemic modals. Forthcoming in Journal of Philosophical Logic. 